\title{
Cost variation analysis study of oral anti-depressant drugs available in India
}

\author{
Chaithra K. N.*, Laxminarayana Kamath
}

Department of Pharmacology, Bangalore Medical College and Research Institute, Bangalore, Karnataka, India

Received: 23 January 2017 Accepted: 27 February 2017

\section{*Correspondence to:}

Dr. Chaithra K. N.,

Email: dr.chaithra@gmail.com

Copyright: (C) the author(s), publisher and licensee Medip Academy. This is an openaccess article distributed under the terms of the Creative Commons Attribution NonCommercial License, which permits unrestricted noncommercial use, distribution, and reproduction in any medium, provided the original work is properly cited.

\begin{abstract}
Background: Depression is a disorder of major public health importance, in terms of its prevalence and the suffering, dysfunction, morbidity and economic burden. In India, the overall prevalence of depression is reported to be $15.9 \%$. Antidepressant drugs are available in many different brands and costs of all brands are different. Patients of depression have to take the antidepressant drug for a long duration, so cost of the antidepressant drug influence the patient adherence to treatment and it is one of the important part of rational prescription.

Methods: The cost of a particular drug being manufactured by different companies in the same strength and dosage forms was obtained from "Current Index of Medical Specialties" July-October, 2015, and "DrugsUpadate.com". The cost ratio and percentage cost variation was calculated.

Results: The prices of a total of 28 drugs (22 single and 6 combination preparations) available in 64 different formulations were analyzed. In single drug therapy, among Tri cyclic antidepressants (TCAs), Reboxetine (2 mg) showed the maximum price variation of $900 \%$. In SSRIs, Dapoxetine $(30 \mathrm{mg}$ ) showed the maximum price variation of $2360 \%$. In SNRIs, Venlafaxine (75 mg) showed the maximum price variation of $109 \%$. In Atypical antidepressants, Bupropion $(150 \mathrm{mg}$ ) showed the maximum price variation of $515.38 \%$. In RIMAs, Moclobemide $(150 \mathrm{mg})$ showed the maximum price variation of $246.15 \%$ and in combination therapies, Amitriptyline with Chlordiazepoxide showed the maximum price variation of $129.35 \%$.

Conclusions: This study shows a wide variation in the prices of oral Antidepressant drugs available in India. Psychiatrist/ Physician should consider the cost while prescribing antidepressant drugs. India being developing country most of the people belong to poor socioeconomic status, so prescribing same generic drug with low cost reduces economic burden and improves patient adherence to treatment which results in better outcome.
\end{abstract}

Keywords: Antidepressant drugs, Brands, Cost analysis, Cost ratio, Price variation

\section{INTRODUCTION}

Depression is a disorder of major public health importance, in terms of its prevalence and the suffering, dysfunction, morbidity, and economic burden. Depression is more common in women than men. The report on global burden of disease estimates the point prevalence of unipolar depressive episodes to be $1.9 \%$ for men and $3.2 \%$ for women, and the one year prevalence has been estimated to be $5.8 \%$ for men and $9.5 \%$ for women. ${ }^{1}$ In India, an overall prevalence of depression is reported to be $15.9 \%$, which is higher than global figures. ${ }^{2}$ Studies done in primary health care settings in India have found depression in $21-84 \%$ of the cases. ${ }^{3,4}$ At its worst, depression can lead to suicide. Almost 1 million lives are lost yearly due to suicide, which translates to 3000 suicide deaths every day. ${ }^{5}$ Antidepressant medications and supportive psychological interventions are effective in about $80 \%$ of patients. ${ }^{6}$

According to survey, Indian pharmaceutical market is 3rd in volume and 13th in value in the world. Branded generic drugs market is $70-80 \%$ in India. Even though production is more in India, still all people do not get 
medicines because of high cost. $^{7}$ In Indian pharmaceutical market there is a huge number of formulations of antidepressant drugs, and the same formulations are sold under different brands. ${ }^{8}$ Prices of drugs are kept at high by manufacturing company and it makes the drug less affordable for poor people. ${ }^{9}$ Pharmaco-economics plays an important role in practice of medicine in developing countries. Majority of healthcare expenditures are paid by the population (67\%-70\%), whereas the government accounts for only 30\%-33\%. The compliance to treatment by the patient is significantly dependent on the cost of the prescribed medicines. $^{7,8}$

Antidepressant drugs are available in many different brands and costs of all brands are different. Patients of depression have to take the antidepressant drug for a longer duration. If the cost of a drug is high patient has to pay more money for complete treatment. It can result in noncompliance and treatment failure. ${ }^{9}$ Lack of knowledge about the cost of various brands of different antidepressant drugs can lead to difficulties in prescribing same effective treatment regime at low cost for the patient. So this study was designed to evaluate the cost of antidepressant drugs of different generic classes and different brand names and to analyse price variation among various antidepressant drugs available in India.

\section{METHODS}

Cost of the particular oral antidepressant drug either single or in combination (Cost per 10 tablets/capsules) in the same strength and dosage forms being manufactured by different companies was obtained from Current Index of Medical Specialties (CIMS) July-October, 2015 and DrugsUpdate.com. The cost was also crosschecked at pharmacy. The drugs manufactured by only one company or by different companies in different strengths and parenteral formulations were excluded.

\section{Data analyses}

The difference between the maximum and minimum cost of a particular generic antidepressant drug (single drug or drug combinations) in the same strength, number, and dosage forms being manufactured by different companies was compared and percentage cost variation in Indian rupees of oral antidepressant drugs was calculated by using following formula. ${ }^{10,11}$

1. Percentage cost variation in Indian rupees

$=$ Price of the most expensive brand-Price of the least expensive brand $* 100$

Price of the least expensive brand

2. Cost ratio $=$ Price of the most expensive brand Price of the least expensive brand

\section{RESULTS}

The prices of a total of 28 drugs (22 single and 6 combination preparations) available in 64 different formulations were analyzed. In a single drug therapy, there is a higher cost difference among the oral antidepressant drugs. Dapoxetine 30mg showed highest cost difference among all the antidepressant drugs (Table 1).

Table 1: Cost difference (Min and Max) of oral antidepressant drugs used as a single therapy.

\begin{tabular}{|lll|}
\hline Drugs & $\begin{array}{l}\text { Minimum cost } \\
\text { (INR) (Per 10 } \\
\text { tablets/capsules) }\end{array}$ & $\begin{array}{l}\text { Maximum cost } \\
\text { (INR) (Per 10 } \\
\text { tablets/capsules) }\end{array}$ \\
\hline $\begin{array}{l}\text { Dapoxetine } \\
\text { 30mg }\end{array}$ & 18.29 & 450 \\
\hline $\begin{array}{l}\text { Reboxetine } \\
\text { 2mg }\end{array}$ & 16 & 160 \\
\hline $\begin{array}{l}\text { Bupropion } \\
\text { 150mg }\end{array}$ & 65 & 400 \\
\hline $\begin{array}{l}\text { Amitriptyline } \\
\text { 50mg }\end{array}$ & 18.3 & 69.33 \\
\hline $\begin{array}{l}\text { Clomipramine } \\
\text { 10mg }\end{array}$ & 15.25 & 54 \\
\hline $\begin{array}{l}\text { Moclobemide } \\
\text { 150mg }\end{array}$ & 19.5 & 67.5 \\
\hline $\begin{array}{l}\text { Dothiepin } \\
\text { 50mg }\end{array}$ & 27 & 76 \\
\hline $\begin{array}{l}\text { Escitalopram } \\
\text { 10mg }\end{array}$ & 30 & 68 \\
\hline $\begin{array}{l}\text { Trazodone } \\
\text { 50mg }\end{array}$ & 19.85 & 44 \\
\hline $\begin{array}{l}\text { Venlafaxine } \\
\text { 50mg }\end{array}$ & 47 & 98 \\
\hline
\end{tabular}

There is a wide variations in cost ratio of antidepressant drugs, Dapoxetine 30mg shows highest cost ratio of 24.6. Cost ratio of Dapoxetine is 24.6 which implies that cost one brand is 24 times higher than other brand for the same generic (Figure 1).

In single drug therapy, among Tri cyclic antidepressants (TCAs), Reboxetine (2mg) showed the maximum price variation of $900 \%$. In Selective Serotonin Reuptake Inhibitors (SSRIs), Dapoxetine $(30 \mathrm{mg})$ showed the maximum price variation of $2360 \%$. In Serotonin and Nor epinephrine Re-uptake Inhibitors (SNRIs), Venlafaxine $(75 \mathrm{mg})$ showed the maximum price variation of $109 \%$. In Atypical antidepressants, Bupropion (150mg) showed the maximum price variation of $515.38 \%$. In RIMAs, Moclobemide $(150 \mathrm{mg})$ showed the maximum price variation of $246.15 \%$ (Figure 2). A total of 6 combinations of drugs were analyzed. In this group Amitriptyline (12.5 mg) + Chlordiazepoxide (5 mg) showed the maximum cost ratio of 2.29, while Escitalopram (10mg) + Etizolam $(0.5 \mathrm{mg})$ showed the minimum price variation of 1.29 (Table 2 ). 


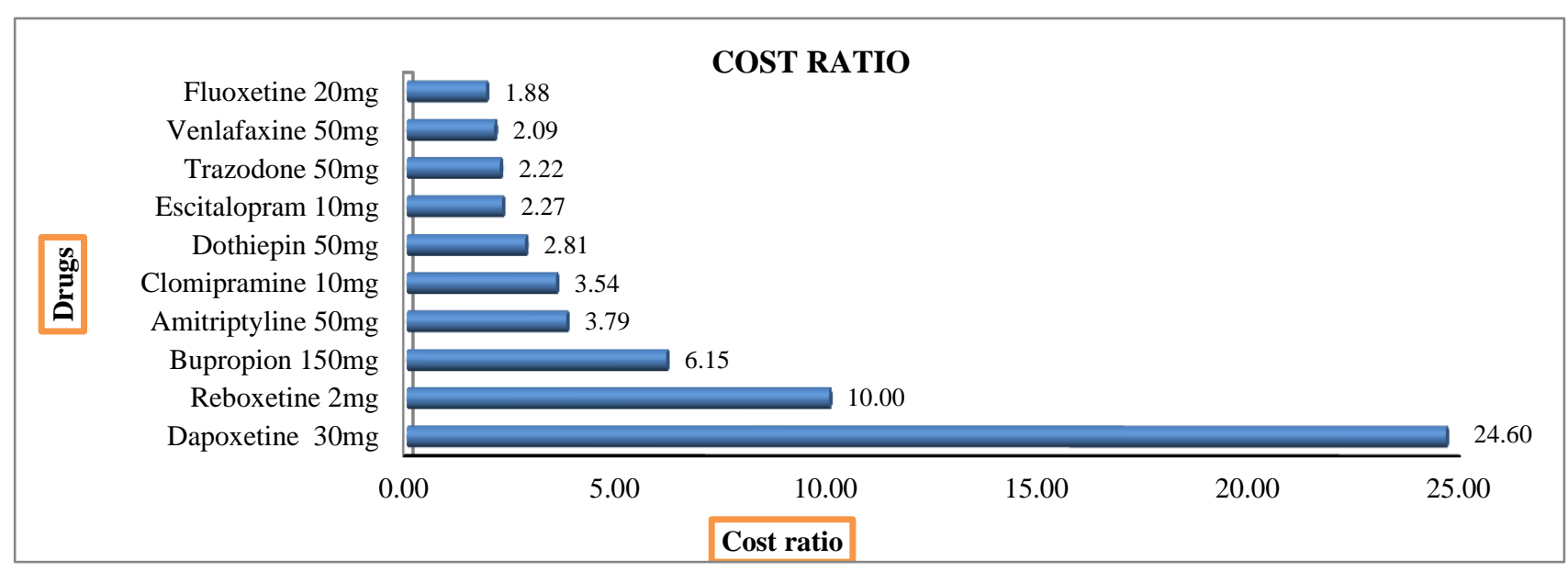

Figure 1: Cost ratio of oral antidepressant drugs used as a single drug therapy.

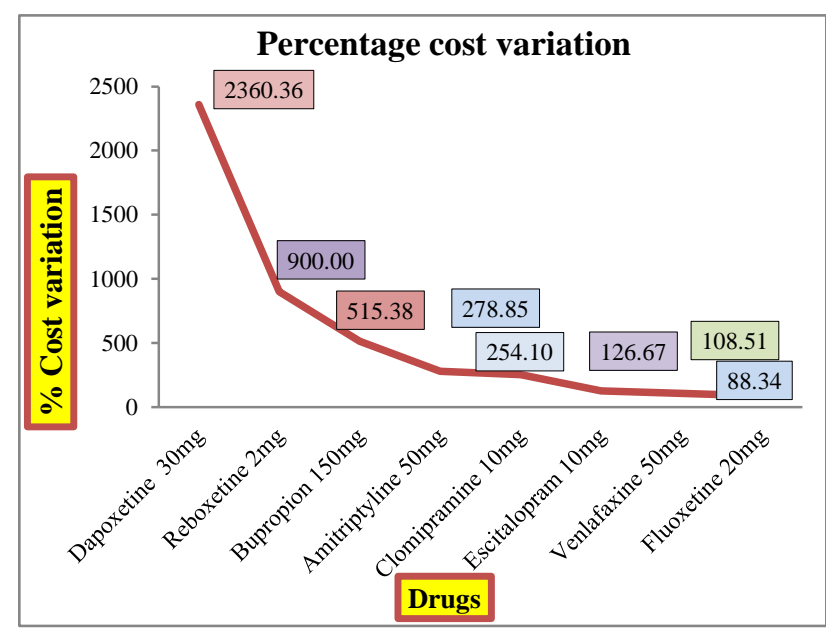

Figure 2: Percentage cost variation of oral antidepressant drugs used as a single drug therapy.

Table 2: Cost ratio of oral antidepressant drug combinations.

\begin{tabular}{|llll|}
\hline Drug combinations & $\begin{array}{l}\text { Minimum } \\
\text { cost (INR) } \\
\text { (Per 10 } \\
\text { tablets/cap } \\
\text { sules) }\end{array}$ & $\begin{array}{l}\text { Maximum } \\
\text { cost (INR) } \\
\text { (Per 10 } \\
\text { tablets/cap } \\
\text { sules) }\end{array}$ & $\begin{array}{l}\text { Cost } \\
\text { ratio }\end{array}$ \\
\hline $\begin{array}{l}\text { Amitriptyline } \\
\text { 12.5mg+Chlordiazepo } \\
\text { xide 5mg }\end{array}$ & 10.9 & 25 & 2.29 \\
\hline $\begin{array}{l}\text { Amitriptyline 25 } \\
\text { mg+Chlordiazepoxide } \\
\text { 10mg }\end{array}$ & 21 & 43.85 & 2.09 \\
\hline $\begin{array}{l}\text { Imipramine } \\
\text { 25mg+Diazepam 2mg }\end{array}$ & 9.5 & 15.11 & 1.59 \\
\hline $\begin{array}{l}\text { Escitalopram 10mg+ } \\
\text { Clonazepam 0.5mg }\end{array}$ & 62.4 & 99 & 1.59 \\
\hline $\begin{array}{l}\text { Escitalopram } \\
\text { 10mg+Etizolam 0.5mg }\end{array}$ & 63 & 81 & 1.54 \\
\hline $\begin{array}{l}\text { Fluoxetine } \\
\text { 20mg+Alprazolam } \\
\text { 0.25mg }\end{array}$ & 25 & 38.5 & 1.29 \\
\hline
\end{tabular}

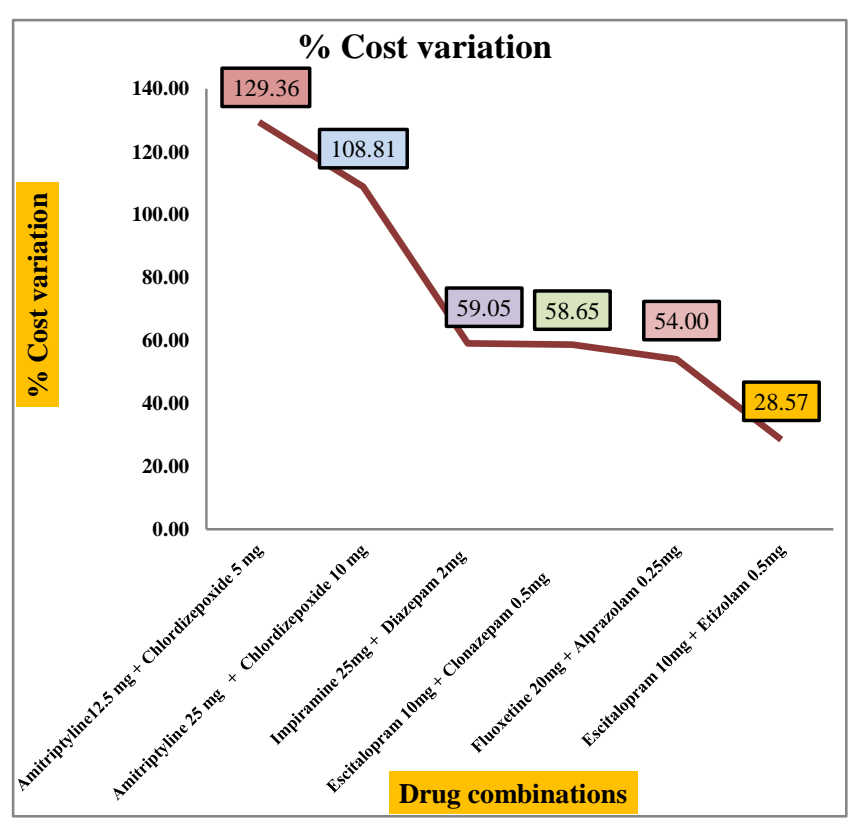

Figure 3: Percentage cost variation of oral antidepressant drug combinations.

In antidepressant drug combinations amitriptyline (12.5 $\mathrm{mg})+$ chlordiazepoxide $(5 \mathrm{mg})$ showed the maximum price variation of $129.36 \%$, while Escitalopram 10mg + Etizolam $0.5 \mathrm{mg}$ showed the minimum price variation of $28.57 \%$ (Figure 3 ).

\section{DISCUSSION}

Rational use of medicines is that the patient receives medication appropriate to the clinical need, at the proper dose, for the proper duration and at the lowest cost. So for rational prescribing, prescriber should also consider the cost while writing prescription along with other criteria of rational use of the drug. ${ }^{10}$

Cost of the drug is an important factor and prescribers are not aware of all different brands of drugs available and 
their prices. So studies about comparing the cost of a different class of drugs and their different brands can provide some knowledge to prescriber about the cost of different drugs in the specific disease condition. Our study results shows, wide variation in the prices of oral anti-depressant drugs available in India. Among different dosage formulation of antidepressant drugs 19 dosage formulations have price variation $100 \%$ or more than $100 \%$, only 1 dosage formulation have price variation $<1 \%$.

In the current study, among the SSRI and SNRI highest price variation was seen with the Dapoxetine $30 \mathrm{mg}$ $(2360 \%)$ and Venlafaxine 50mg (108.5\%) respectively where as in the study conducted by Bhumika et al Escitalopram 10mg (495.23\%) and Duloxetine 20mg shown highest price variation. ${ }^{8}$ In atypical antidepressants Bupropion showed highest price variation of $515 \%$ which is similar to the study conducted by Paunikar AP where in the Bupropion shown the highest price variation of $447.94 \%$. $^{9}$ Reason for this differences may be the increasing number of manufacturing companies and increasing price of a particular drug by manufacturing companies.

In drug combinations, the Amitriptyline $12.5 \mathrm{mg}+$ Chlordiazepoxide $5 \mathrm{mg}$ showed highest cost ratio of 2.29 and Escitalopram $10 \mathrm{mg}+$ Etizolam $0.5 \mathrm{mg}$ showed the least cost ratio 1.29. As both the above drug combination are proven to be equally efficacious prescriber can choose the later combination as it has lesser cost.

Escitalopram $10 \mathrm{mg}+$ Etizolam $0.5 \mathrm{mg}$ showed the price variation of $28.57 \%$ where as in the study conducted by Bhumika et al Escitalopram 10mg alone showed the price variation of $495.23 \%$ and in the present study it showed $126.67 \%$ variation. $^{4}$

Drug prices are controlled according to drug price control order (DPCO), ceiling price of drugs are fixed by national pharmaceutical pricing authority (NPPA government of India in accordance with DPCO). The price of drugs is revised every year according to the wholesale price index. For current year compendium of prices has been released by NPPA, it is showing ceiling price fixed for current year and includes 509 drug formulations which includes essential medicine list 2011. ${ }^{12}$ There were $80-85 \%$ of drugs in 1979 and $15-20 \%$ drugs in 2002 were under price control in India. ${ }^{13}$

All antidepressant drugs are not under DPCO. Drugs in the national list of essential medicine and included in DPCO 2015 are Amitriptyline 25mg tablets, Fluoxetine hydrochloride $20 \mathrm{mg}$ capsules, Imipramine $25 \mathrm{mg}$ and $75 \mathrm{mg}$ tablets also shows high price variation of $125 \%$, $88 \%, 50$ and $48 \% \%$ respectively in our study. Compared to the other anti-depressant drugs Fluoxetine $20 \mathrm{mg}$ and Imipramine $25 \mathrm{mg}$ have lesser price variation whereas the Amitriptyline $25 \mathrm{mg}$ has the higher price variation even though it is under DPCO.
Study of price variation has been done for antipsychotic, anti diabetic and antihypertensive drugs, they also found wide price variation among various brand of drugs. ${ }^{14-16}$ There should be undergraduate teaching about the cost of medicine because the price of drugs is variable. Practical exercise can be kept for a particular disease to find the cheapest medicine from all the brands, find total brands available for a particular drug and to calculate the cost of therapy. The doctor who is prescribing the medicines should have data for cost of different drugs that can be done by providing updated information of cost of various brand of drugs in the manual. ${ }^{13,15}$

The pharmacist also has role in this system. Some pharmacist don't give the same brand of drug that is prescribed, they change it and give some costly branded drug. Pharmacist has monetary benefit in selling that brand of drug. ${ }^{17}$

Availability of only expensive brand of drugs for the same generic drug in Pharmacy store, necessitate the patient to buy that brand of drug. Because of the expensive brands, they buy only a few medicines and they will not complete the course of treatment, patient continues to be diseased. It has been seen that there are 2fold to100-fold variations in price of drugs so it becomes tough for prescribing doctor to choose the drug. ${ }^{18}$

Government of India has opened few generic drug stores in some states that sell generic medicines manufactured by public sector companies. The quality of generic medicines available on these stores at cheaper rates should be tested and compared with popular branded drugs and results should be widely published. Studies involving comparative evaluation on quality of branded and their generic counterpart may be made mandatory for the generic manufacturer and their reports should be made public to promote generic use and prescription. ${ }^{19}$

In India pricing of drugs system should be regularized. Drugs under DPCO have minimum cost variation compared to the drugs not under control. There is no addition of any antidepressant drugs in DPCO 2015 compared to 2013; GOI should address the issues regarding this. Including most of the drugs under DPCO can help in reducing percentage cost variation.

\section{CONCLUSION}

Our study findings show a wide variation in the prices of different brands of same antidepressant drugs in India. In India the system for pricing the drugs should be regularized. There is a strong need to create awareness about this higher price variation among the general public, health care providers, health care payers, government agencies, policy makers, pharmacists for appropriate intervention to reduce economic burden on patients as well as the healthcare system. Our study results help the prescriber to select the same generic drug at low cost, 
which improves patient adherence to the treatment as well fulfils the one of the criteria of rational prescription.

\section{ACKNOWLEDGEMENTS}

Authors would like to thank all the faculty of department of pharmacology for helping in this research work.

Funding: No funding sources

Conflict of interest: None declared

Ethical approval: The study was approved by the Institutional Ethics Committee

\section{REFERENCES}

1. Lopez AD, Mathers CD, Ezzati M, Jamison DT, Murray CJ. Global Burden of Disease and Risk Factors. Washington: The World Bank; 2006.

2. Poongothai S, Pradeepa R, Ganesan A, Mohan V. Prevalence of depression in a large urban South Indian population-The Chennai Urban Rural Epidemiology Study (CURES-70). PloS One. 2009;4:E7185.

3. Pothen M, Kuruvilla A, Philip K, Joseph A, Jacob KS. Common mental disorders among primary care attenders in Vellore, South India: Nature, prevalence and risk factors. Int J Soc Psychiatry. 2003;49:11925.

4. Amin G, Shah S, Vankar GK. The prevalence and recognition of depression in primary care. Indian $\mathbf{J}$ Psychiatry. 1998;40:364-39.

5. WHO: Depression -A Global Public Health Concern. 2012.

6. Reddy MS. Depression: The disorder and the burden. Indian J Psychol Med. 2010;32:12.

7. Das SC, Mandal M, Mandal SC. A critical study on availability and price variation between different brands: Impact on access to medicines. Indian J Pharm Sci. 2007;69(1):160-3.

8. Patel V, Chatterjji S, Chisholm D, Ebrahim S, Gopalakrishna G, Mathers C. Chronic diseases and injuries in India. Lancet. 2011;377(9763):413-28.
9. Paunikar AP, Bhave KA. Cost analysis of oral antidepressant drugs available in India. Nat $\mathrm{J}$ Physiol Pharm Pharmacol. 2015;5(5):1-5.

10. Patel BJ, Patel KH, Patel MP. Antidepressant drugs: evaluation of price variation. Int $\mathbf{J}$ Basic Clin Pharmacol. 2015;4(3):432-37.

11. Jadhav NB, Bhosale MS, Adhav CV. Cost analysis study of oral antidiabetic drugs available in Indian market. Int J Med Res Health Sci. 2013;2(1):63-9.

12. Compendium of notified ceiling prices of scheduled drugs. NPPA; 2015.

13. Jana S, Mondal P. Pharmacoeconomics: the need to sensitize undergraduate medical students. Indian J Pharmacol. 2005;37:277-8.

14. Tondare SB, Bhave KA. Cost analysis of oral antipsychotic drugs available in the Indian market. Int J Pharm Sci Rev Res. 2014;29(2):267-70.

15. Date AP, Mahajan HM, Dashputra AV, Bhosale RR. Study of variation in price of various antidiabetic drugs available in Indian market. Int $\mathbf{J}$ Basic Clin Pharm. 2015;4:36-40.

16. Karve AV, Chattar KB. Cost analysis study of oral antihypertensive agents available in Indian market. IJBCP. 2014;3(3):479-83.

17. Roy N, Madhiwala N. Promotional Practices of Pharmaceutical Firms in India. Forum for Medical Ethics, Mumbai; 2004.

18. Lofolm PW, Katzug BG. Rational prescribing and prescription writing. In: katzung $\mathrm{BG}$, editor. Basic and Clinical Pharmacology. $9^{\text {th }}$ Ed. New York: McGraw Hill; 2004:1091-1100.

19. Kamath L, Satish GR. Cost Variation Analysis of Antihypertensive Drugs Available in Indian Market: An Economic Perspective. Int J Pharm Sci Res. 2016;7(5):2050-56.

Cite this article as: Chaithra KN, Kamath L. Cost variation analysis study of oral anti-depressant drugs available in India. Int J Basic Clin Pharmacol 2017;6:973-7. 